Article

\title{
Preparation and Properties of Tumor-Targeting MRI Contrast Agent Based on Linear Polylysine Derivatives
}

\author{
Xuanrong Sun *D, Yue Cai, Zhuomin Xu and Dabu Zhu \\ Collaborative Innovation Center of Yangtze River Delta Region Green Pharmaceuticals, \\ Zhejiang University of Technology, Hangzhou 310014, China; chinacaiyue@163.com (Y.C.); \\ zhuominX9551@163.com (Z.X.); 15757116042@163.com (D.Z.) \\ * Correspondence: sunxr@zjut.edu.cn; Tel.: +86-57188871566
}

Received: 14 February 2019; Accepted: 14 April 2019; Published: 15 April 2019

check for updates

\begin{abstract}
We developed a tumor-targeted contrast agent based on linear polylysine (PLL) by conjugating a small molecular imaging agent, fluorescent molecule and targeting agent amino phenylboronic acid onto the amino groups of polylysine, which can specifically target monosaccharide sialic acid residues overexpressing on the surface of tumor cell membranes. Further, 3,4,5,6-Tetrahydrophthalic anhydride (DCA) was attached to the free amino groups of the polylysine to change to a negative charge at physiology $\mathrm{pH}$ to lower the cytotoxicity, but it soon regenerated to a positive charge again once reaching the acidic intratumoral environment and therefore increased cell uptake. Laser confocal microscopy images showed that most of the polymeric contrast agents were bound to the cancer cell membrane. Moreover, the tumor targeting contrast agent showed the same magnetic resonance imaging (MRI) contrasting performance in vitro as the small molecule contrast agent used in clinic, which made it a promising tumor-targeting polymeric contrast agent for cancer diagnosis.
\end{abstract}

Keywords: magnetic resonance imaging (MRI); polylysine; tumor targeting; charge reversal

\section{Introduction}

Cancer can be eradicated by chemotherapy, surgery and other methods in its early stages, but by the time it has metastasized, these methods almost never make a difference [1,2]. Therefore, accurate diagnosis of early tumors can greatly improve the survival rate and quality of life of patients [3]. Magnetic resonance imaging (MRI), as a safe, rapid and accurate clinical diagnosis method causing no harm to the human body, plays a wide role in tumor diagnosis and treatment $[4,5]$.

Contrast agent (CA) is one of the most commonly used drugs in interventional radiology operations, which can effectively improve MRI sensitivity [6,7]. The application of small molecule gadolinium chelates in clinic has many disadvantages, such as nonspecificity, short survival time in vivo and low mobility [8]. In recent years, research on large molecule Gd chelates has become highly sought after. It has the advantages of high relaxation efficiency, low cytotoxicity and good tumor targeting [9], which can be better used in MRI tumor diagnosis [10,11]. However, the efficiency of macromolecular Gd chelates is still unsatisfactory. Only a small portion of CAs can reach the tumor site through the EPR effect, and most CAs remain in blood circulation or clear very quickly. Therefore, introducing some targeting groups to modify the CAs can achieve active binding to specific sites and enhance accumulation on tumor cell surface, which can further reduce toxicity for normal tissues and improve the contrast signals between the tumor and the surrounding tissues.

Tumor cells overexpressing sialic acid (Sia) appear protected against the immune defense system, and, as a result, malignancy is increased [12,13]. Numerous studies have demonstrated that sialic 
acid residues are relevant biomarkers of metastatic activity of tumors [14], and that the amount of Sia expression on cancer cells correlates with the prognosis of patients $[15,16]$. Phenylboronic acid (pba) moiety can recognize Sia on the cancer cell surface based on the reversible formation of fiveand six-membered cyclic boronic acid/boronate esters between pha and the exocylic polyol function of Sia [17]. More importantly, phenylboronic acid/phenylboronate esters and their end products are considered nontoxic to humans [18-20]. Therefore, they are considered a potential candidate for active targeting the highly expressed Sia moiety in tumor cells.

Herein, polylysine (PLL) was used as a backbone, and we utilized a large number of amine groups in its side chain and afterwards linked with small molecule contrast agents, fluorescent dye and tumor-targeting groups boronic acid to obtain a novel polymeric contrast agent for active targeting of tumor cells. Meanwhile, the excess amino groups in PLL were treated by 3,4,5,6-tetrahydrophthalic anhydride (DCA) so that the whole contrast agent molecules exhibited a negative charge at physiological $\mathrm{pH}$ and resulted in less toxicity to the cells. Once reaching tumor sites, the anhydride in DCA quickly hydrolyzed and regenerated the original amine groups carrying cationic charge due to the tumor acidic environment [21-23], therefore significantly increasing the uptake of the contrast agent by the cancer cells and the selectively enhanced tumor imaging ability of the contrast agent.

\section{Results and Discussion}

\subsection{Polymer Characterization}

Due to a large amount of amine groups in the side chain, polylysine was selected as the backbone of the contrast agent and was fully utilized to conjugate functional groups such as small molecule contrast agents $\left(\mathrm{Gd}^{3+}\right)$, fluorescent dye (Rhodamine) and boric acid groups (B). We obtained two different $\mathrm{B} \%$ content tumor-targeted MRI contrast agents. In addition, DCA was used to neutralize the extra amine groups in PLL to make the whole agent exert negative charges to avoid cytotoxicity while circulating in the blood. When reaching the tumor site, DCA hydrolyzed quickly in an acid environment and released the positive PLL-based contrast agent, thereby increasing the cancer cells' uptake of themselves. The designed tumor-targeting contrast agent structure is shown in Figure 1. The ${ }^{1} \mathrm{H}-\mathrm{NMR}$ spectrum verification of every compound is given in the Supplementary Material.

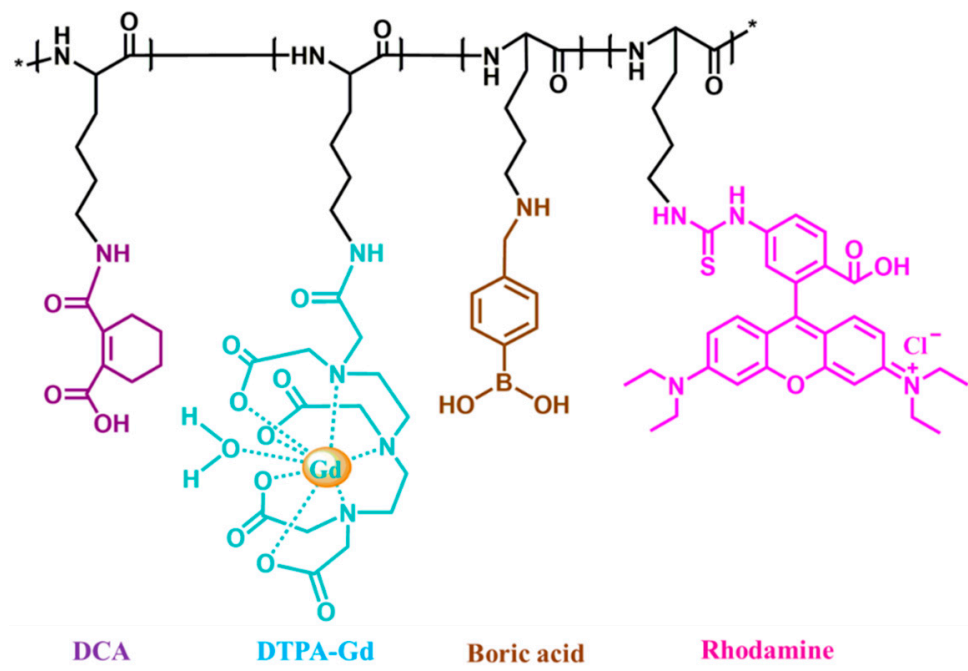

Figure 1. Schematic of tumor-targeting contrast agent PLL-B-DTPA-Gd-Rodamine-DCA. A series of functional groups, such as small molecule contrast agents $\left(\mathrm{Gd}^{3+}\right)$, fluorescent dye (Rhodamine) and tumor-targeting group (boric acid groups) B were conjugated with the amine groups on the side chain of polylysine (PLL). The 3,4,5,6-tetrahydrophthalic anhydride (DCA) was also conjugated to neutralize the extra amine groups in PLL to make the whole agent exert negative charges. 
The molecular weight of synthesized PLL was measured by GPC (gel permeation chromatography) using $N, N$-Dimethylformamide (DMF) as the mobile phase. It showed that PLL synthesized has a weight average molecular weight of $4 \times 10^{4}$ with PDI 1.2, suggesting we have obtained a uniformly distributed PLL polymer (Figure 2).

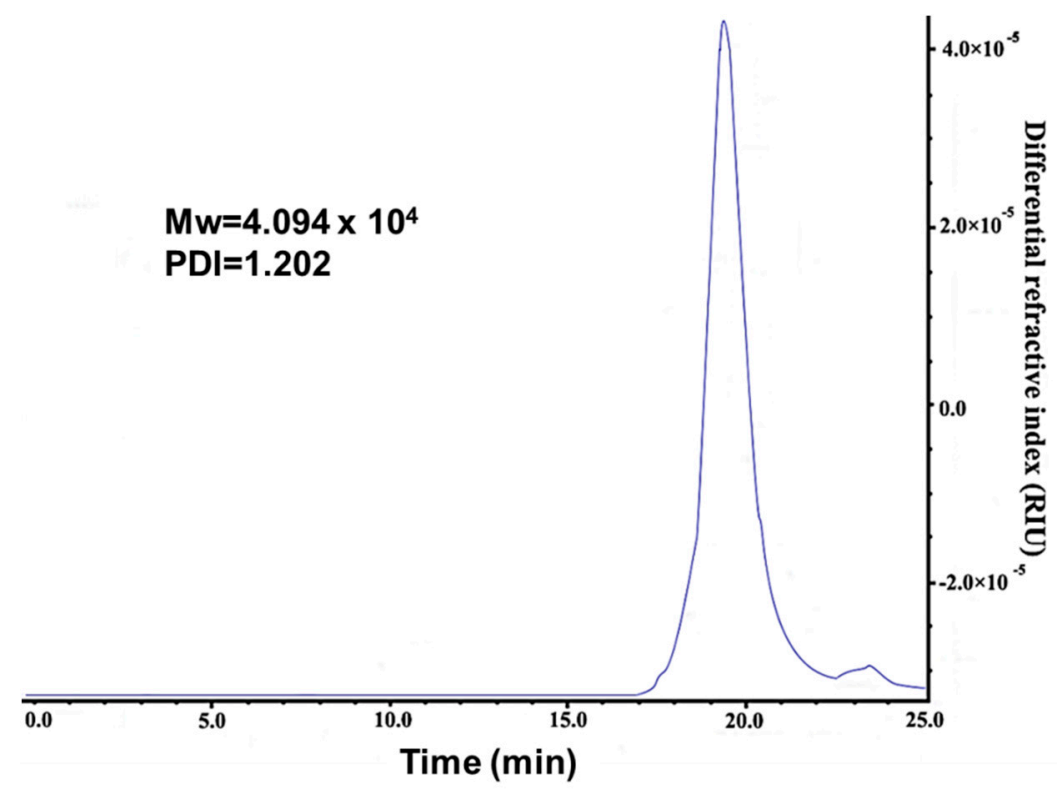

Figure 2. Molecular-weights of synthesized PLL measured by gel permeation chromatography (GPC) using dimethyl formamide (DMF) as the mobile phase.

To verify the content of small molecule contrast agent $\mathrm{Gd}^{3+}$ that had conjugated in PLL, inductively coupled plasma mass spectrometry (ICP-MS) was performed with both PLL-B(1\%)-DTPA-GdRodamine-DCA and PLL-B(5\%)-DTPA-Gd-Rodamine-DCA. The Gd ${ }^{3+}$ content in PLL-B(1\%)-DTPAGd-Rodamine-DCA was therefore calculated as $5.4 \%$; the $\mathrm{Gd}^{3+}$ content in PLL-B(5\%)-DTPAGd-Rodamine-DCA was $7.8 \%$.

Furthermore, both PLL-B(1\%)-DTPA-Gd-Rodamine-DCA and PLL-B(5\%)-DTPA-Gd-RodamineDCA could form a water-soluble, clear and transparent solution if left for more than one month at room temperature, and no obvious aggregation could be seen during this period.

\subsection{Charge Reversal Effect Confirmation}

To confirm that DCA had successfully conjugated with PLL and can lead to a charge reversal effect, $\zeta$-potential value was determined using laser Doppler anemometry for both DCA-conjugated PLL and unconjugated PLL (Table 1). This demonstrated that before conjugatation with DCA, the $\zeta$-potential value of PLL-B(1\%)-DTPA-Gd-Rodamine was $30.1 \mathrm{mV}$, and after DCA treatment it dropped to $-16.5 \mathrm{mV}$. The same trend was found for PLL-B(5\%)-DTPA-Gd-Rodamine: before DCA treatment the charge was about $31.7 \mathrm{mV}$, and after treatment it dropped to $-28.7 \mathrm{mV}$, indicating that DCA can achieve a charge reversal effect, from positive to negative transition, when at physiology $\mathrm{pH}$. Moreover, when incubating with pH 5.0 acid buffer for $1 \mathrm{~h}$, the $\zeta$-potentials of PLL-B(1\%)-DTPA-Gd-Rodamine-DCA and PLL-B(5\%)-DTPA-Gd-Rodamine-DCA were again reversed to positive charge $22.1 \mathrm{mV}$ and $20.2 \mathrm{mV}$, respectively, suggesting that conjugated DCA hydrolyzed quickly in the acid environment and therefore led to breakage from the PLL side chains and charge reverse, which may increase the cell uptake in the tumor interstitium. 
Table 1. $\zeta$-potential of PLL-B-DTPA-Gd-Rodamine and PLL-B-DTPA-Gd-Rodamine-DCA in different conditions.

\begin{tabular}{cccc}
\hline & PLL-B(1\%)-DTPA-Gd- & PLL-B(1\%)-DTPA-Gd- & PLL-B(1\%)-DTPA-Gd- \\
& Rodamine in pH 7.4 & Rodamine-DCA in pH 7.4 & Rodamine-DCA in pH 5.0 \\
$\zeta$-potential & $30.1 \mathrm{mV}$ & $-16.5 \mathrm{mV}$ & $22.1 \mathrm{mV}$ \\
& PLL-B(5\%)-DTPA-Gd- & PLL-B(5\%)-DTPA-Gd- & PLL-B(5\%)-DTPA-Gd- \\
& Rodamine in pH 7.4 & Rodamine-DCA in pH 7.4 & Rodamine-DCA in pH 5.0 \\
$\zeta$-potential & $31.7 \mathrm{mV}$ & $-28.8 \mathrm{mV}$ & $20.2 \mathrm{mV}$ \\
\hline
\end{tabular}

\subsection{Longitudinal Relaxivity $\left(R_{1}\right)$ Measurement}

To further investigate the imaging enhancement capability of the synthesized contrast agent, the $\mathrm{T}_{1}$ of PLL-B(5\%)-DTPA-Gd solutions was determined on a $0.52-\mathrm{T}$ MR system at $32{ }^{\circ} \mathrm{C}$ and the $R_{1}$ s were calculated from the slope of the curves of $1 / T_{1}$ against the $\mathrm{Gd}^{3+}$ concentration shown in Figure 3A. The $1 / T_{1}$ was linear with the $\mathrm{Gd}^{3+}$ concentration and the $\mathrm{R}_{1}$ of DTPA-Gd (Magnevist ${ }^{\circledR}$ ) was about $4.3 \mathrm{mM}^{-1} \mathrm{~s}^{-1}$, which was similar to that reported in previous literature [24]. The relaxation rate $\left(\mathrm{R}_{1}\right)$ of PLL-B(5\%)-DTPA-Gd was about $4.5 \mathrm{mM}^{-1} \mathrm{~s}^{-1}$, which was nearly the same as the small molecule contrast agent DTPA-Gd subjected to a magnetic field intensity of about $0.52 \mathrm{~T}$ at $32{ }^{\circ} \mathrm{C}$. It was generally expected that macromolecular $\mathrm{Gd}$ chelate could hinder the water exchange between the coordinated $\mathrm{H}_{2} \mathrm{O}$ and bulk $\mathrm{H}_{2} \mathrm{O}$ around $\mathrm{Gd}$ chelate and therefore decrease $\mathrm{R}_{1} \mathrm{~s}[25,26]$. On the other hand, the conjugation of DTPA-Gd onto the rigid linear PLL polymer could increase the rigidity of the polymer and its rotational correlation time $\left({ }_{\tau} R\right)$ and therefore increase $R_{1} s$ [27]. Therefore, the novel contrast agent PLL-B(5\%)-DTPA-Gd can exhibit comparable imaging enhancement to the DTPA-Gd (Magnevist $^{\circledR}$ ) used in clinic.
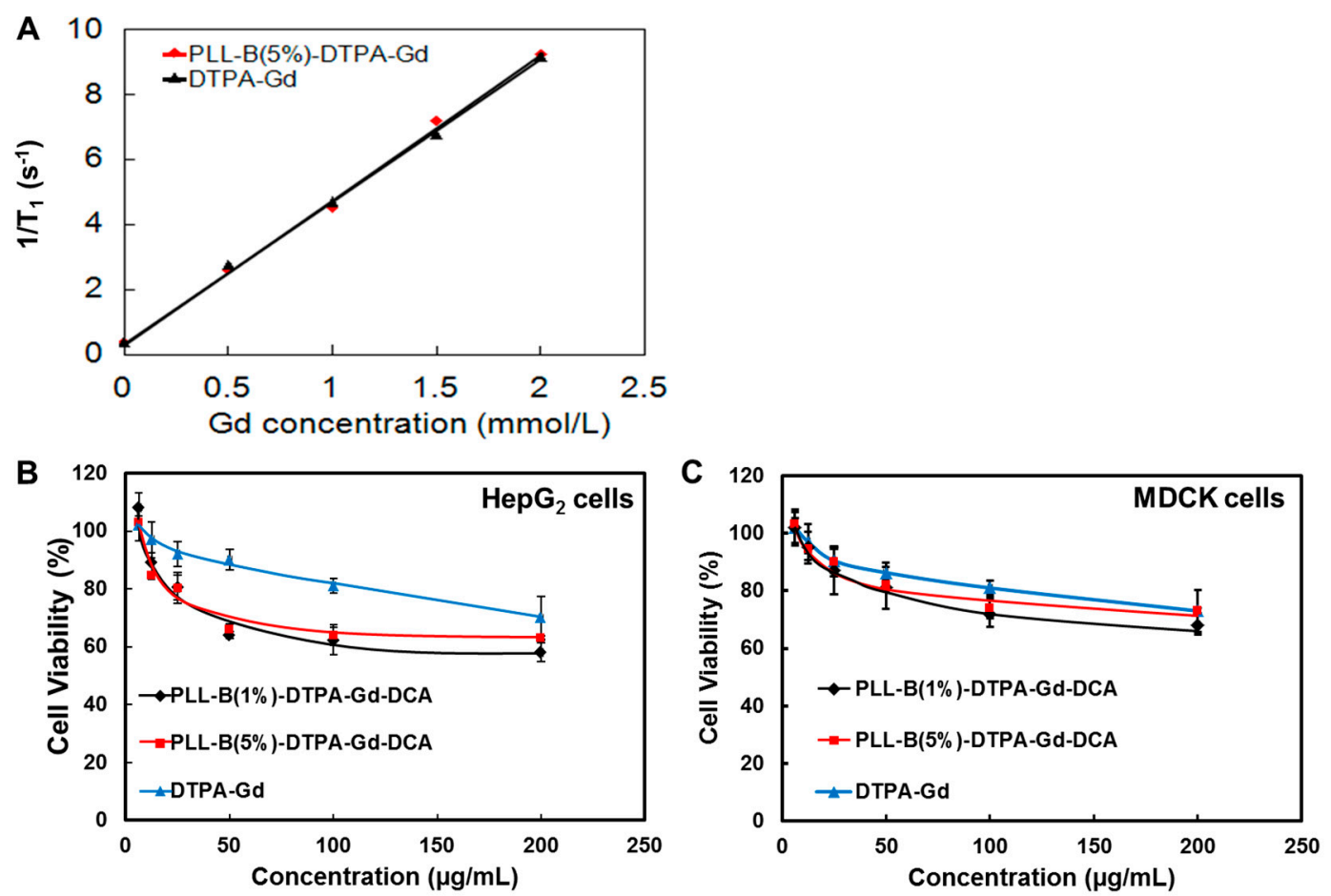

Figure 3. (A) Relaxation rates of PLL-B(5\%)-DTPA-Gd and DTPA-Gd solutions at different concentrations $\left(0.52 \mathrm{~T}\right.$ and $\left.32^{\circ} \mathrm{C}\right)$. Cytotoxicity of PLL-B(1\%)-DTPA-Gd-Rodamine-DCA and PLL-B(5\%)DTPA-Gd-Rodamine-DCA to $\mathrm{HepG}_{2}$ cells (B) and Madin-Darby Canine Kidney (MDCK) cells (C), estimated by MTT assay. Cells were cultured in DMEM medium for $24 \mathrm{~h}$. All solid lines are fitted to the data. 


\subsection{In Vitro MTT Assay}

As PLL has been reported as maintaining some cytotoxicity in a panel of cell lines, due to the large amount of positive charge on the surface [28], the cytotoxicity of this novel PLL-based tumor-targeted magnetic resonance contrast agent was determined by MTT assay using $\mathrm{HepG}_{2}$ lung cancer cells as the model cancer cells and healthy dog kidney cells (Madin-Darby Canine Kidney (MDCK)) as the normal cells for comparing with small contrast agent DTPA-Gd. As Figure 3B shows, the cell proliferation ability was not significantly affected when drug concentration was around $20 \mu \mathrm{g} / \mathrm{mL}$. As the drug concentration increased to $50 \mu \mathrm{g} / \mathrm{mL}$, cancer cell growth was affected to some extent, but the viability rate was still above $65 \%$. Even when the drug concentration increased to $200 \mu \mathrm{g} / \mathrm{mL}$, cell viability rate could still maintain around $65 \%$, which meant the majority of cells were still alive during incubation with PLL derivatives. Moreover, the cell viability of both PLL-B(1\%)-DTPA-Gd-DCA and PLL-B(5\%)-DTPA-Gd-DCA showed no significant difference in $\mathrm{HepG}_{2}$ cancer cells, indicating that both PLL-B(1\%)-DTPA-Gd-DCA and PLL-B(5\%)-DTPA-Gd-DCA had good biocompatibility at concentrations below $20 \mu \mathrm{g} / \mathrm{mL}$. However, when the concentrations were increased to higher than $100 \mu \mathrm{g} / \mathrm{mL}$, both agents showed cytotoxicity to some extent.

When treating normal MDCK cells, both agents showed less cytotoxicity than for cancer cells. This result may be attributed to the fact that PLL-B-DTPA-Gd-DCA with phenylboronic acid can more easily recognize the malignant cells, because sialic acid residues selectively highly overexpressed in the malignant cancer cells but not in the normal cells, and therefore accumulated more and led to higher cytotoxicity in cancer cells. Meanwhile, DTPA-Gd had also shown some but less cytotoxicity in $\mathrm{HepG}_{2}$ cells and MDCK cells. Even when the concentration reached $200 \mu \mathrm{g} / \mathrm{mL}$, cell viability was still maintained at above $70 \%$.

\subsection{Tumor Cells Targeting Ability Measurement}

It has been reported that sialic acid residues are highly overexpressed on the surface of malignant cancer cells and can easily be recognized by diol-phenylboronic acid (PBA) [29]. Therefore, the targeting ability of the PBA-based imaging contrast agent on both cancer cells and normal cells was determined by laser confocal microscope, as shown in Figure 4, and mean fluorescent intensity for each group was analyzed by Image J software. Compared to normal cells, PLL-B(1\%)-DTPA-Gd-Rodamine-DCA and PLL-B(5\%)-DTPA-Gd-Rodamine-DCA contrast agents were mostly distributed across the cancer cell $\mathrm{HepG}_{2}$ membrane, indicating that the boric acid groups of the polymers can specifically bind to the sialic acid residue's structure on the cell membrane (Figure 4A,B) whereas on the normal cells, PLL-B(5\%)-DTPA-Gd-Rodamine-DCA exhibited nearly no accumulation on the normal cells due to little sialic acid residues expressed in the normal cells (MDCK cells) (Figure 4C). The mean fluorescent intensity of binding ability showed significant difference between cancer cells and normal cells which strengthen the statement previously reported (Figure 4F).

Unfortunately, we did not observe any endocytosis, even when we incubated the PLL-B-DTPA-GdRodamine-DCA with $\mathrm{HepG}_{2}$ cancer cells for $2 \mathrm{~h}$. There may be two reasons for this: first, as PBA has a high affinity to sialic acid, the polymer that conjugated with PBA may initially recognize the sialic acid on the cell membrane and bind tightly with it, and therefore delay the time for endocytosis. Thus, the polymers may be internalized if the polymers are incubated for a longer time. Second, it has been reported that boric acid can recognize some glucose proteins, such as p-gp, on the cell membrane; therefore, the polymer may be efflux from the membrane after a certain period of incubation. Further study of modifying the polymers for enhancing endocytosis is still under way.

In addition, the target ability of $5 \%$ content of boronic acid contrast agent showed no significant difference to $1 \%$ boric acid content contrast agent, which may indicate that $1 \%$ content of boric acid has already reached the saturation concentration for boric acid targeting ability.

Furthermore, it is reported that boronic acids can bind to glucose, which is an abundant saccharide in the culture medium or blood. Thus, we tested whether glucose could lead to the suppression of polymers binding to tumor cells. We incubated both the PLL-B(1\%)-DTPA-Gd-Rodamine-DCA 
and PLL-B(5\%)-DTPA-Gd-Rodamine-DCA in either a glucose-free medium or a glucose-containing medium, and we found that there was nearly the same fluorescent intensity on the cell membrane in both medium, indicating that tumor-targeting ability was not affected by the glucose in the medium (Figure $4 \mathrm{~A}$ vs. Figure $4 \mathrm{D}$, Figure $4 \mathrm{~B}$ vs. Figure $4 \mathrm{E}, \mathrm{F}$ ). The lower affinity of boronic acid to glucose than to Sia is due to the fact that $\mathrm{d}(+)$ glucose is present in the solution predominantly $(>99 \%)$ in its pyranose anomeric form, which cannot combine with boronic acid.
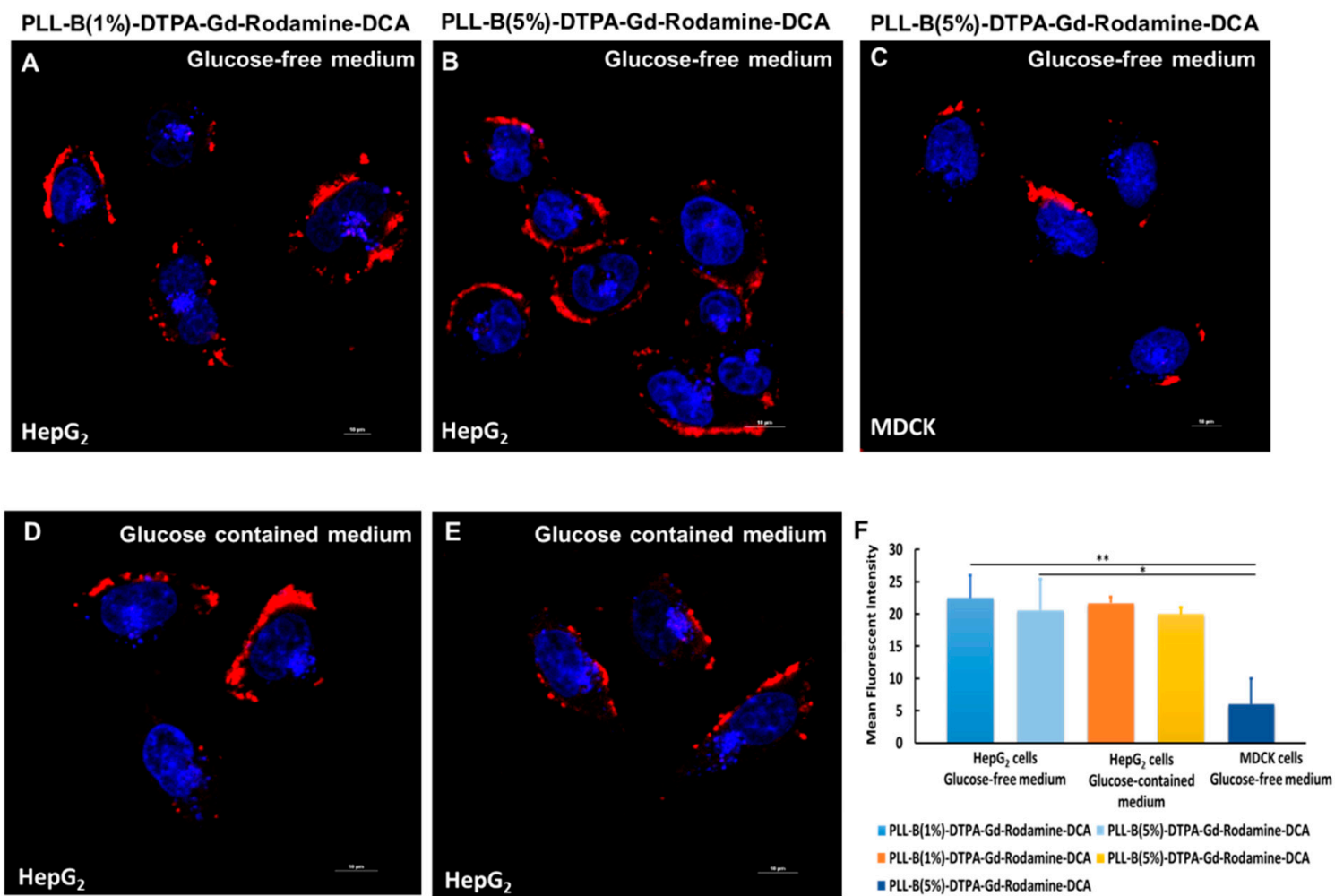

Figure 4. Intracellular colocalization of (A) PLL-B(1\%)-DTPA-Gd-Rodamine-DCA on HepG 2 cellsin glucose-free medium; (B) PLL-B(5\%)-DTPA-Gd-Rodamine-DCA with cytomembrane on $\mathrm{HepG}_{2}$ cells in glucose-free medium; (C) PLL-B(5\%)-DTPA-Gd-Rodamine-DCA on MDCK cells in glucose-free medium; (D) PLL-B(1\%)-DTPA-Gd-Rodamine-DCA on HepG 2 cells in glucose-containing medium; (E) PLL-B(5\%)-DTPA-Gd-Rodamine-DCA on $\mathrm{HepG}_{2}$ cells in glucose-containing medium (Blue: DRAQ5; Red: PLL-B(1\%)-DTPA-Gd-Rodamine-DCA/PLL-B(5\%)-DTPA-Gd-Rodamine-DCA); (F) Image-based quantification of mean fluorescent intensity statistic using Image J software. Data represent the average fluorescent intensity of each group. ${ }^{*} p<0.05,{ }^{* *} p<0.01$.

In addition, Sakata et al. reported that phenylboronic acids were shown to be unable to bind to alpha-anomer of sialic acid, which is the dominant anomer, but bind to beta-anomer, which leads to the conclusion that PBA cannot selectively recognize the SA unit or discriminate between specific types of cell [30]. However, the structures of phenylboronate species also need to be taken into consideration. In our study, the complex showed positively charged when entering into the living cancer cells. The sialic acids are a family of $\mathrm{C}_{9}$ monosaccharides with a carboxyl group at the anomeric carbon atom $(\mathrm{pKa}=2.2)$ that gives the molecule a negative charge at physiological $\mathrm{pH}$. Therefore, it facilitated the recognition mechanism through electrostatic affinity to the negatively charged carboxylic groups of the Sia residues. Furthermore, the interaction between boric acid and SA may differ in the living cells because of the existence of serum and other proteins. Consequently, the PLL-B-DTPA-Gd-Rodamine-DCA derivatives shown in this study to have the ability to bind to the sialic acid residues structure on the cell membrane are reasonable. 


\section{Materials and Methods}

\subsection{Materials and Measurements}

All the organic solvents were purchased from Sinopharm Chemical Reagent Co., Ltd. (Shanghai, China). Dimethyl sulfoxide was purified by distillation under vacuum over calcium hydride. Gadolinium chloride hexahydrate $\left(\mathrm{GdCl}_{3} \cdot 6 \mathrm{H}_{2} \mathrm{O}\right)$ was bought from Alfa Aesar (Ward Hill, MA, USA). The cellulose ester dialysis membrane (molecular weight cut off, $\mathrm{MWCO}=10,000$ ) was purchased from Spectrum Laboratories Inc. (Rancho Dominguez, CA, USA). Amicon Ultra-15 centrifugal filter devices (MWCO = 10,000) were purchased from Millipore (Cork, Ireland).

The ${ }^{1} \mathrm{H}-\mathrm{NMR}$ spectra were recorded on a Bruker Avance DRX-400 NMR spectrometer (Bruker, Switzerland,) at room temperature. The sizes (hydrodynamic diameters) of the PCAs were measured using a dynamic light scattering instrument (Zetasizer Nano ZS, Malvern Instruments, Worcestershire, $\mathrm{UK})$. Concentrations of $\mathrm{Gd}^{3+}$ solutions were measured by inductively coupled plasma mass spectrometry (ICP-MS, XSeries II, Thermo Scientific, Waltham, MA, USA). Gel permeation chromatography (GPC) was performed on a Wyatt GPC/SEC-MALS (Wyatt Technology Corporation, Santa Barbara, CA, USA) system equipped with a DAWN ${ }^{\circledR}$ HELEOS $^{\circledR}$ II 18-angle static light scattering detector (Wyatt Technology Corporation, Santa Barbara, CA, USA) and an Optilab ${ }^{\circledR}$ T-rEXTM refractive index detector (Wyatt Technology Corporation, Santa Barbara, CA, USA), and three columns (Wyatt Technology Corporation, Santa Barbara, CA, USA) in series (a MZ GPC-PRECOLUMN $50 \times 8.0 \mathrm{~mm}$ MZ-Gel SDplus $100 \AA 10 \mu \mathrm{m}$, a $300 \times 8.0 \mathrm{~mm}$ MZ-Gel SDplus $10 \mathrm{E} 4 \AA 10 \mu \mathrm{m}$ and a $300 \times 8.0 \mathrm{~mm}$ MZ-Gel SDplus $100 \AA 10 \mu \mathrm{m})$ at $50{ }^{\circ} \mathrm{C}$ using DMF containing $50 \mathrm{mM} \mathrm{LiBr}$ as eluent at a flow rate of $0.80 \mathrm{~mL} \mathrm{~min}^{-1}$. Data were recorded and processed with ASTRA v6.0 (Wyatt Technology Corporation, Santa Barbara, USA) software.

The human hepatocellular carcinoma cell line $\mathrm{HepG}_{2}$ and the Madin-Darby Canine Kidney (MDCK) cell line were purchased from the China Center for Type Culture Collection (Wuhan, China).

\subsection{Preparation and Processing}

\subsubsection{Synthesis of PLL}

First, PLL was prepared using the methods reported in reference [31]. Details of the experimental procedures are as follows (Figure 5). The NCA derivatives were prepared by the method of Daly and Poche, with exceptions as noted below.
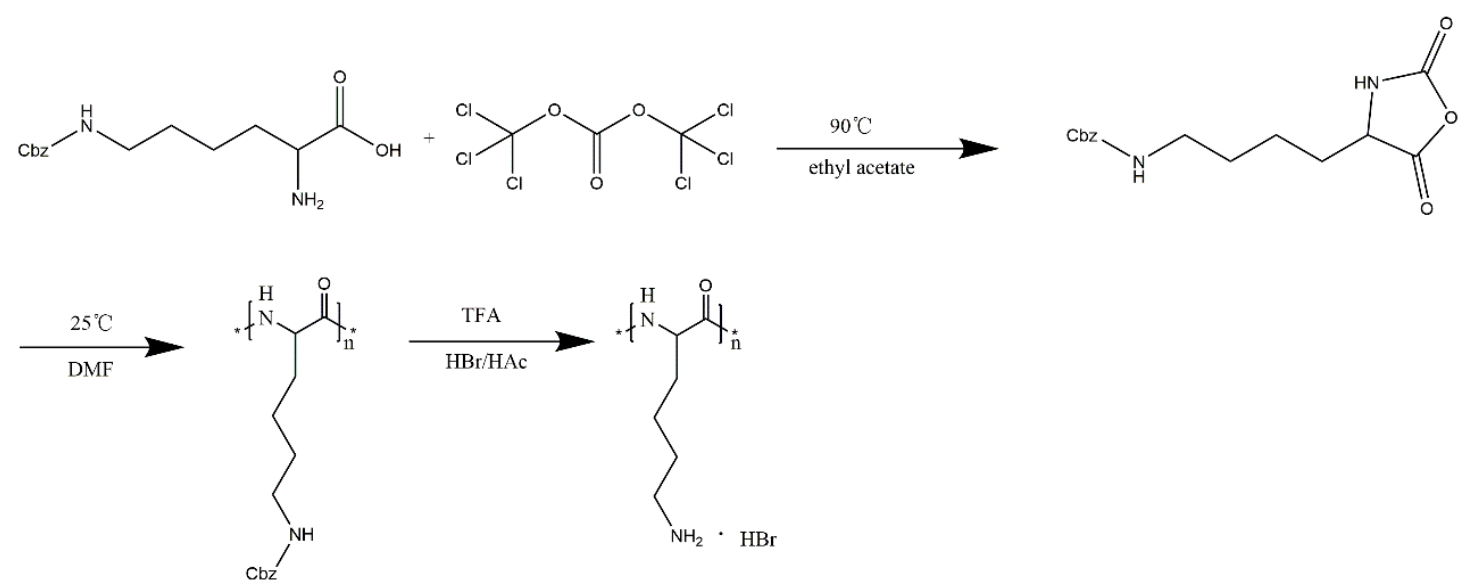

Figure 5. Synthesis route of PLL.

Preparation of NCA:

$N$-carboxyanhydrides that are isolated as oils should use no more than $1 / 3$ of an equivalent of triphosgene and typically 10-20\% less. 
Ten grams of H-Lys(z)-OH were suspended in $150 \mathrm{~mL}$ of anhydrous ethyl acetate in a reaction flask fitted with a reflux condenser and $\mathrm{N}_{2}$ bubbler. After heating to reflux, $6.5 \mathrm{~g}$ of triphosgene were added at once and the reaction allowed to reflux under $\mathrm{N}_{2}$ for $4-5 \mathrm{~h}$. Generally, the reaction became clear. The reaction was allowed to cool down to room temperature, which in some cases caused a solid (presumably the $\mathrm{HCl}$ salt of the starting amino acid) to precipitate. The reaction was then cooled in the stoppered reaction vessel to $-5{ }^{\circ} \mathrm{C}$.

The cold reaction was washed with $100 \mathrm{~mL}$ of de-ionized water, chilled to $0{ }^{\circ} \mathrm{C}$. The ethyl acetate layer was then washed with $100 \mathrm{~mL}$ of $0.5 \% w / v \mathrm{NaHCO}_{3}$, chilled to $0{ }^{\circ} \mathrm{C}$. Anhydrous $\mathrm{MgSO}_{4}$ was used to dry the ethyl acetate layer. The clear solution was gravity filtered and concentrated to about $1 / 3$ its original volume on a rotary evaporator below $30^{\circ} \mathrm{C}$. An equal volume of hexane or petroleum ether (30-60 ${ }^{\circ} \mathrm{C}$ cut) was then added to induce crystallization of the NCA. After chilling to $-5{ }^{\circ} \mathrm{C}$ overnight, the NCA crystals were collected by suction filtration in a dry, $\mathrm{N}_{2}$ environment.

Polymerizations:

First, $9.2 \mathrm{~g}$ of NCA obtained from the last step were dissolved in $25 \mathrm{~mL}$ of dry DMF. One drop $(<0.01 \mathrm{~mL})$ of triethylamine was then added to the stirred solution. After stirring for three days, the polymer was dialyzed using an MW $=3500$ dialysis bag to remove the DMF, and finally a white, lumpish solid (PLL-CBZ) was obtained.

\section{PLL-CBZ deprotection:}

The PLL-CBZ (8.7 g) was dissolved in $20 \mathrm{~mL}$ of trifluoroacetic acid (TFA) and $16 \mathrm{~mL}$ of $\mathrm{HBr} / \mathrm{HAc}$ $(33 \mathrm{wt} \%)$ was added dropwise, a bulk precipitate was gradually formed and stirred continuously at room temperature overnight. Five-fold volume excess of THF was added, centrifuged and repeated three times on the next day. The resulting white precipitate was dissolved in $50 \mathrm{~mL}$ of de-ionized water, placed in a MW $=3500$ dialysis bag, and dialyzed for $24 \mathrm{~h}$. The dialysate was taken out and lyophilized.

\subsubsection{Synthesis of Boric Acid Conjugated PLL (PLL-B)}

Synthesis route of PLL-B was as follows (Figure 6). Polylysine $(0.2 \mathrm{~g}, 1.02 \mathrm{mmol} \mathrm{NH}$ ) was dissolved in $5 \mathrm{~mL}$ anhydrous methanol. Anhydrous sodium sulfate $(0.5 \mathrm{~g})$ and 4 -formylbenzeneboronic acid $\left(1.53 \mathrm{mg}, 0.01 \mathrm{mmol} \mathrm{NH}_{2}\right)$ were added and stirred at room temperature for $5 \mathrm{~h}$. After the reaction, anhydrous sodium sulfate was removed by suction filtration, and sodium borohydride $(1.16 \mathrm{mg}$, $0.0153 \mathrm{mmol}$ of $\mathrm{NH}_{2}$ ) was added. The mixture was stirred continuously at room temperature for another $4 \mathrm{~h}$. The anhydrous methanol was removed by rotary evaporation. The resulting solid was dissolved in $5 \mathrm{~mL}$ of water and then placed in a MW $=3500$ dialysis bag and dialyzed for $24 \mathrm{~h}$. The dialysate was taken out and lyophilized, and the obtained product was PLL-B (1\%).
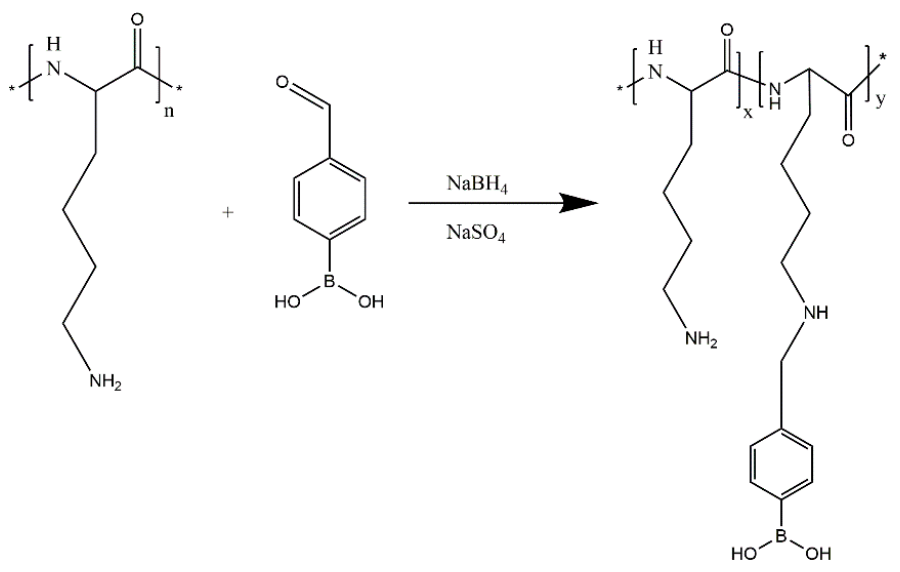

Figure 6. Synthesis route of PLL-B. 


\subsubsection{Synthesis of PLL-B-DTPA}

The PLL-B-DTPA was prepared by the methods shown in Figure 7. The PLL-B ( $0.2 \mathrm{~g}, 1.01 \mathrm{mmol}$ $\mathrm{NH}_{2}$ ) was dissolved in $5 \mathrm{~mL}$ of water, then DTPA-NHS $\left(9.09 \mathrm{mmol} \mathrm{NH}_{2}\right)$ was added and stirred at room temperature overnight. After the reaction was completed, the resulting solution was placed in a $\mathrm{MW}=3500$ dialysis bag and dialyzed for $24 \mathrm{~h}$. The dialysate was taken out and lyophilized, and the obtained product was PLL-B(1\%)-DTPA. The DTPA content is about $26 \%$ in terms of the integrated area.

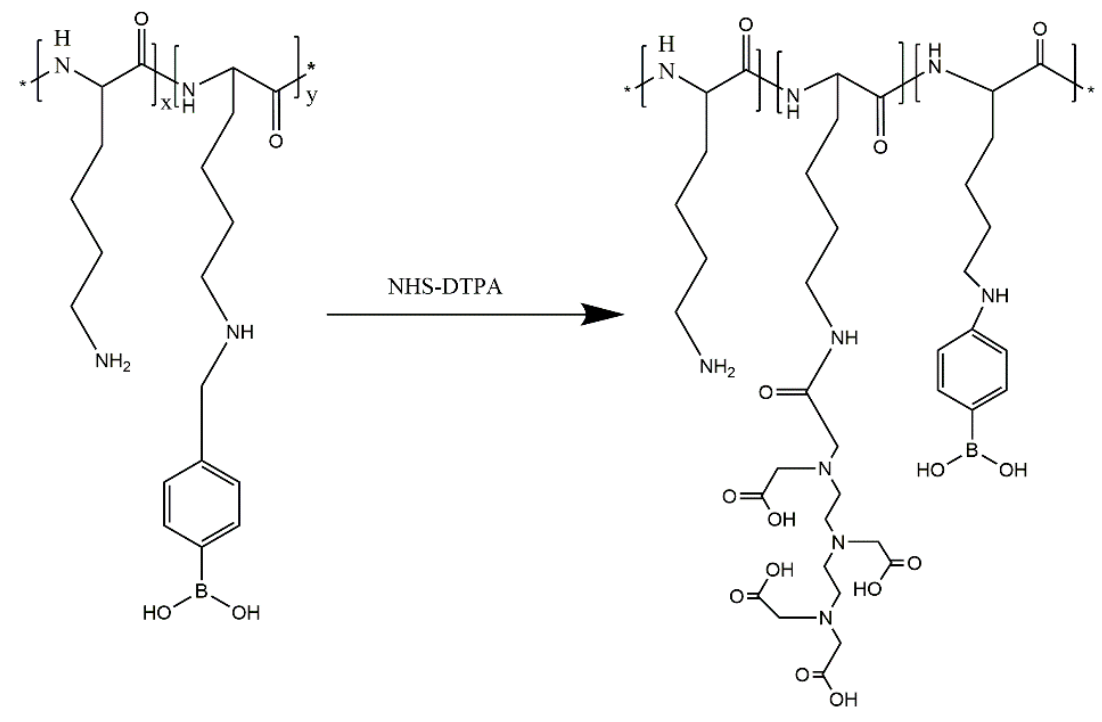

Figure 7. Synthesis route of PLL-B-DTPA.

\subsubsection{Synthesis of PLL-B-DTPA-Gd}

The PLL-B(1\%)-DTPA (0.505 mmol DTPA) was dissolved in $5 \mathrm{~mL}$ water. Then, $3 \mathrm{~mL}$ aqueous solution of cesium acetate $\left(2 \times 10^{-4} \mathrm{~mol} / \mathrm{mL}, 1.2 \mathrm{eq}\right)$ was added and stirred at room temperature for $2 \mathrm{~h}$. After the reaction was completed, the resulting solution was placed in an ultrafiltration centrifuge tube and centrifuged at $4000 \mathrm{r} / \mathrm{min}$ for $30 \mathrm{~min}$. The supernatant was taken out and lyophilized. The obtained product was PLL-B(1\%)-DTPA-Gd.

\subsubsection{Tumor-Targeted Magnetic Resonance Contrast Agent Fluorescent Labelling}

Figure 8 shows the synthesis route of PLL-B-DTPA-Rodamine. The PLL-B(1\%)-DTPA-Gd $(0.1 \mathrm{~g})$ was dissolved in $5 \mathrm{~mL}$ of water. Rhodamine isothiocyanate $(1 \mathrm{mg})$ was added and stirred at room temperature for $8 \mathrm{~h}$ (Figure 8). After the reaction was completed, the resulting solution was placed in a MW $=3500$ dialysis bag and dialyzed for $24 \mathrm{~h}$ and lyophilized. The resulting product was PLL-B(1\%)-DTPA-Gd-Rodamine.

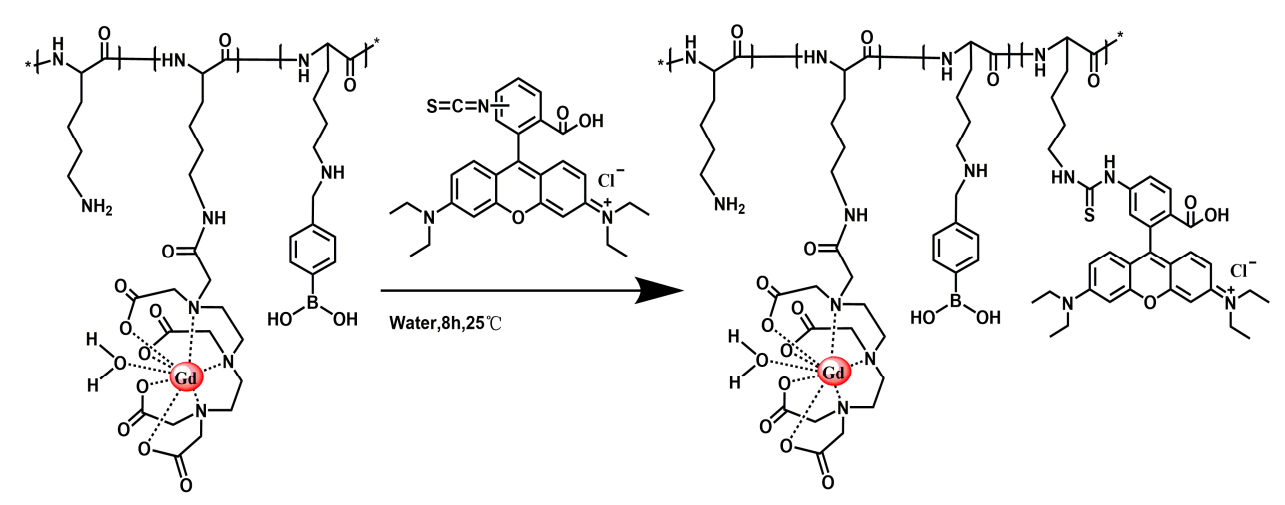

Figure 8. Synthesis route of PLL-B-DTPA-Rodamine. 


\subsubsection{Synthesis of PLL-B(1\%)-DTPA-Gd-Rodamine-DCA}

The PLL-B(1\%)-DTPA-Gd-Rodamine $(0.5 \mathrm{~g})$ was dissolved in $5 \mathrm{~mL}$ water. The DCA $(1 \mathrm{~g})$ was added and stirred at room temperature for $8 \mathrm{~h}$ (Figure 9). After the reaction was completed, the resulting solution was placed in a MW $=3500$ dialysis bag and dialyzed for $24 \mathrm{~h}$ and lyophilized. The obtained product was PLL-B(1\%)-DTPA-Gd- Rodamine-DCA.

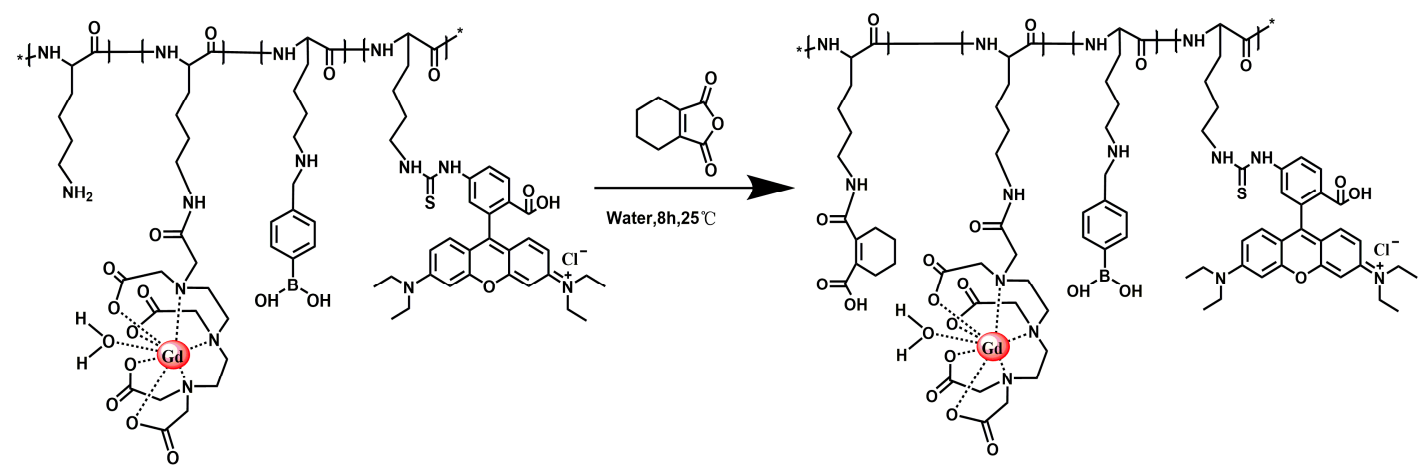

Figure 9. Synthesis route of PLL-B-DTPA-Rodamine-DCA.

\subsection{Polymer Characterization}

Concentrations of $\mathrm{Gd}^{3+}$ solutions were measured by inductively coupled plasma mass spectrometry (ICP-MS, XSeries II, Thermo Scientific, MA, USA).

The sizes (hydrodynamic diameters) of the PCAs were measured using a dynamic light scattering instrument (Zetasizer Nano ZS, Malvern Instruments, UK).

Gel permeation chromatography was performed on a Wyatt GPC/SEC-MALS (Wyatt Technology Corporation, Santa Barbara, USA) system equipped with a DAWN ${ }^{\circledR}$ HELEOS $^{\circledR}$ II 18-angle static light scattering detector and an Optilab ${ }^{\circledR}$ T-rEXTM refractive index detector, and three columns in series (a MZ GPC-PRECOLUMN $50 \times 8.0 \mathrm{~mm}$ MZ-Gel SDplus $100 \AA 10 \mu \mathrm{m}$, a $300 \times 8.0 \mathrm{~mm}$ MZ-Gel SDplus $10 \mathrm{E} 4 \AA 10 \mu \mathrm{m}$ and a $300 \times 8.0 \mathrm{~mm}$ MZ-Gel SDplus $100 \AA 10 \mu \mathrm{m})$ at $50^{\circ} \mathrm{C}$ using DMF containing $50 \mathrm{mM}$ $\mathrm{LiBr}$ as eluent at a flow rate of $0.80 \mathrm{~mL} \mathrm{~min}^{-1}$. Data were recorded and processed with ASTRA v6.0 (Wyatt Technology Corporation, Santa Barbara, USA) software.

The ${ }^{1} \mathrm{H}-\mathrm{NMR}$ spectra were recorded on a Bruker Avance DRX-400 NMR spectrometer at room temperature.

\subsection{Longitudinal Relaxivity $\left(R_{1}\right)$ Measurement}

The longitudinal relaxation times $\left(\mathrm{T}_{1}\right)$ were measured with a 0.52-T MicroMR Imaging and Analyzing System (Shanghai Niumag Corporation, Shanghai, China) at $32{ }^{\circ} \mathrm{C}$. The $\mathrm{T}_{1}$ values of $\mathrm{CA}$ solutions with different $\mathrm{Gd}$ concentrations ranging from 0.5 to $2 \mathrm{mM}$ in water were measured. The $\mathrm{R}_{1}$ values of CAs were defined by Formula (1).

$$
\left(1 / \mathrm{T}_{1}\right)_{\mathrm{obs}}=\left(1 / \mathrm{T}_{1}\right)_{\mathrm{d}}+\mathrm{R}_{1} \times[\mathrm{Gd}]
$$

where $[G d]$ is the $G d$ concentration, $\left(1 / T_{1}\right)_{\text {obs }}$ is the observed relaxation rate, and $\left(1 / T_{1}\right)_{d}$ is the relaxation rate of water protons. The plot of $\left(1 / \mathrm{T}_{1}\right)_{\mathrm{obs}} \mathrm{vs}[\mathrm{Gd}]$ gave $\mathrm{R}_{1}$ as its slope.

\subsection{In Vitro MTT Assay}

The cytotoxicity assay was carried out using the 3-(4,5-dimethylthiazol-2-yl)-2,5-diphenyltetrazolium bromide (MTT) cell proliferation kit (ATCC, Manassas, VA, USA). The $\mathrm{HepG}_{2}$ lung cancer cells were seeded in 96-well plates at an initial density of 4000 cells/well in $100 \mu \mathrm{L}$ of DMEM medium and incubated for $24 \mathrm{~h}$. The PLL-B(1\%)-DTPA-Gd-DCA and PLL-B(5\%)-DTPA-Gd-DCA in DMEM $(100 \mu \mathrm{L})$ were added to the medium at different concentrations. Each concentration was replicated in 3 wells. 
Treated cells were incubated at $37{ }^{\circ} \mathrm{C}$ in humidified air with $5 \% \mathrm{CO}_{2}$ for $48 \mathrm{~h}$. The MTT solution $(0.75 \mathrm{mg} / \mathrm{mL})$ was then added to the wells for an additional 3-h incubation. Finally, $200 \mu \mathrm{L}$ DMSO was added to each well, replacing the original medium to dissolve the formazan crystals. The absorbance in each well was determined at $562 \mathrm{~nm}$ using a microplate reader. The cell viability was calculated by Formula (2).

Relative cell viability $(\%)=$ Absorption test/Absorption control $\times 100 \%$

\subsection{Tumor Cells Targeting Ability Measurement}

The targeting effect of the drug on the cell membrane was observed by confocal microscope (Nikon A1, Kyushu, Japan). First, $1 \mathrm{~mL}$ of the medium which contains $1.5 \times 10^{5} \mathrm{HepG}_{2}$ cells or MDCK cells was inoculated into a confocal culture dish with a glucose-free medium or a glucose-containing medium. After $24 \mathrm{~h}$ incubation the medium was replaced, then PLL-B(1\%)-DTPA-Gd-Rodamine-DCA and PLL-B(5\%)-DTPA-Gd-Rodamine-DCA were added respectively. After incubation for $3 \mathrm{~h}$, the medium was discarded and the lysosomal dye Lysotracker Green was added, culturing for another $2 \mathrm{~h}$. Then, the lysosomal dye was washed away, the nuclear dye DRAQ5 was added and the medium was incubated for $15 \mathrm{~min}$. Finally, the medium was drained and washed three times with $0.01 \mathrm{M}$ PBS buffer. Then, the distribution of the drugs on the cells was observed under confocal microscope.

\section{Conclusions}

In summary, two PLL-B-DTPA-Gd-Rodamine-DCA derivatives with different contents of boric acid group as the tumor-targeting group on their surface were successfully prepared and characterized. The novel polymeric contrast agent showed a comparable contrast capability compared with DTPA-Gd used in clinic and good tumor targeting ability in vitro. Further in vivo contrasting performance is still under investigation. The moderate contrast properties, its facile synthesis and good biocompatibility, provide us with a new strategy for designing a novel contrast agent for early detection and diagnosis of tumors.

Supplementary Materials: The following are available online. Figure S1: ${ }^{1} \mathrm{H}-\mathrm{NMR}$ spectra of PLL in $\mathrm{D}_{2} \mathrm{O}$, Figure S2: ${ }^{1} \mathrm{H}-\mathrm{NMR}$ spectra of PLL-B $(1 \%)$ in $\mathrm{D}_{2} \mathrm{O}$, Figure S3: ${ }^{1} \mathrm{H}-\mathrm{NMR}$ spectra of PLL-B $(5 \%)$ in $\mathrm{D}_{2} \mathrm{O}$, Figure S4: ${ }^{1} \mathrm{H}-\mathrm{NMR}$ spectra of PLL-B(1\%)-DTPA in $\mathrm{D}_{2} \mathrm{O}$, Figure S5: ${ }^{1} \mathrm{H}-\mathrm{NMR}$ spectra of PLL-B(5\%)-DTPA in $\mathrm{D}_{2} \mathrm{O}$.

Author Contributions: Data curation, X.S. and Z.X.; Investigation, X.S., Y.C., Z.X. and D.Z.; Writing-original draft, X.S. and Y.C.; Writing-review and editing, X.S. and Y.C.

Funding: This work was supported by grants from the National Natural Science Foundation of China (No. 21506192) and the Zhejiang Provincial Natural Science Foundation of China (No. LY16E030010).

Conflicts of Interest: There are no conflict of interest to declare.

\section{References}

1. Balch, C.M.; Buzaid, A.C.; Soong, S.J.; Atkins, M.B.; Cascinelli, N.; Coit, D.G.; Fleming, I.D.; Gershenwald, J.E.; Houghton, A.J.; Kirkwood, J.M.; et al. Final version of the American Joint Committee on Cancer staging system for cutaneous melanoma. J. Clin. Oncol. 2001, 19, 3635-3648. [CrossRef] [PubMed]

2. Jemal, A.; Bray, F.; Center, M.M.; Ferlay, J.; Ward, E.; Forman, D. Global cancer statistics. CA Cancer J. Clin. 2011, 61, 69-90. [CrossRef]

3. Bruix, J.; Llovet, J.M. Prognostic prediction and treatment strategy in hepatocellular carcinoma. Hepatology 2002, 35, 519-524. [CrossRef] [PubMed]

4. Nelson, S.J. Analysis of volume MRI and MR spectroscopic imaging data for the evaluation of patients with brain tumors. Magn. Reson. Med. 2001, 46, 228-239. [CrossRef]

5. Nakanishi, K.; Kobayashi, M.; Nakaguchi, K.; Kyakuno, M.; Hashimoto, N.; Onishi, H.; Maeda, N.; Nakata, S.; Kuwabara, M.; Murakami, T.; et al. Whole-body MRI for detecting metastatic bone tumor: Diagnostic value of diffusion-weighted images. Magn. Reson. Med. Sci. 2007, 6, 147-155. [CrossRef] 
6. Caravan, P.; Ellison, J.J.; McMurry, T.J.; Lauffer, R.B. Gadolinium(III) Chelates as MRI Contrast Agents: Structure, Dynamics, and Applications. Chem. Rev. 1999, 99, 2293-2352. [CrossRef]

7. Bellin, M.F. MR contrast agents, the old and the new. Eur. J. Radiol. 2006, 60, 314-323. [CrossRef] [PubMed]

8. Villaraza, A.J.; Bumb, A.; Brechbiel, M.W. Macromolecules, dendrimers, and nanomaterials in magnetic resonance imaging: The interplay between size, function, and pharmacokinetics. Chem. Rev. 2010, 110, 2921-2959. [CrossRef]

9. Maeda, H.; Wu, J.; Sawa, T.; Matsumura, Y.; Hori, K. Tumor vascular permeability and the EPR effect in macromolecular therapeutics: A review. J. Control. Release 2000, 65, 271-284. [CrossRef]

10. Lu, Z.R.; Parker, D.L.; Goodrich, K.C.; Wang, X.; Dalle, J.G.; Buswell, H.R. Extracellular biodegradable macromolecular gadolinium(III) complexes for MRI. Magn. Reson. Med. 2004, 51, 27-34. [CrossRef] [PubMed]

11. Doiron, A.L.; Chu, K.; Ali, A.; Brannon-Peppas, L. Preparation and initial characterization of biodegradable particles containing gadolinium-DTPA contrast agent for enhanced MRI. Proc. Natl. Acad. Sci. USA 2008, 105, 17232-17237. [CrossRef]

12. Kannagi, R.; Izawa, M.; Koike, T.; Miyazaki, K.; Kimura, N. Carbohydrate-mediated cell adhesion in cancer metastasis and angiogenesis. Cancer Sci. 2004, 95, 377-384. [CrossRef]

13. Schauer, R. Sialic acids: Fascinating sugars in higher animals and man. Zoology 2004, 107, 49-64. [CrossRef]

14. Martinez-Duncker, I.; Salinas-Marin, R.; Martinez-Duncker, C. Towards in vivo imaging of cancer sialylation. Int. J. Mol. Imaging 2011, 2011, 283497. [CrossRef]

15. Cazet, A.; Julien, S.; Bobowski, M.; Krzewinski-Recchi, M.; Harduin-Lepers, A.; Groux-Degroote, S.; Delannoy, P. Consequences of the expression of sialylated antigens in breast cancer. Carbohyd. Res. 2010, 345, 1377-1383. [CrossRef]

16. Fernandez-Briera, A.; Garcia-Parceiro, I.; Cuevas, E.; Gil-Martin, E. Effect of Human Colorectal Carcinogenesis on the Neural Cell Adhesion Molecule Expression and Polysialylation. Oncology-Basel 2010, 78, 196-204. [CrossRef]

17. Djanashvili, K.; Frullano, L.; Peters, J.A. Molecular recognition of sialic acid end groups by phenylboronates. Chem. Eur. J. 2005, 11, 4010-4018. [CrossRef]

18. Naito, M.; Ishii, T.; Matsumoto, A.; Miyata, K.; Miyahara, Y.; Kataoka, K. A Phenylboronate-Functionalized Polyion Complex Micelle for ATP-Triggered Release of siRNA. Angew. Chem. Int. Edit. 2012, 51, 10751-10755. [CrossRef]

19. Wang, J.; Wu, W.; Zhang, Y.; Wang, X.; Qian, H.; Liu, B.; Jiang, X. The combined effects of size and surface chemistry on the accumulation of boronic acid-rich protein nanoparticles in tumors. Biomaterials 2014, 35, 866-878. [CrossRef]

20. Lee, J.; Chung, S.; Cho, H.; Kim, D. Phenylboronic Acid-Decorated Chondroitin Sulfate A-Based Theranostic Nanoparticles for Enhanced Tumor Targeting and Penetration. Adv. Funct. Mater. 2015, 25, 3705-3717. [CrossRef]

21. Helmlinger, G.; Yuan, F.; Dellian, M.; Jain, R.K. Interstitial pH and pO2 gradients in solid tumors in vivo: High-resolution measurements reveal a lack of correlation. Nat. Med. 1997, 3, 177-182. [CrossRef]

22. Jain, R.K. Delivery of molecular medicine to solid tumors: Lessons from in vivo imaging of gene expression and function. J. Control. Release 2001, 74, 7-25. [CrossRef]

23. Lee, Y.; Fukushima, S.; Bae, Y.; Hiki, S.; Ishii, T.; Kataoka, K. A protein nanocarrier from charge-conversion polymer in response to endosomal pH. J. Am. Chem. Soc. 2007, 129, 5362. [CrossRef]

24. Ye, M.; Qian, Y.; Tang, J.; Hu, H.; Sui, M.; Shen, Y. Targeted biodegradable dendritic MRI contrast agent for enhanced tumor imaging (vol 169, pg 239, 2013). J. Control. Release 2013, 172, 258. [CrossRef]

25. Toth, E.; van Uffelen, I.; Helm, L.; Merbach, A.E.; Ladd, D.; Briley-Saebo, K.; Kellar, K.E. Gadolinium-based linear polymer with temperature-independent proton relaxivities: A unique interplay between the water exchange and rotational contributions. Magn. Reson. Chem. 1998, 36, S125-S134. [CrossRef]

26. Doble, D.M.J.; Botta, M.; Wang, J.; Aime, S.; Barge, A.; Raymond, K.N. Raymond, Optimization of the relaxivity of MRI contrast agents: Effect of poly(ethylene glycol) chains on the water-exchange rates of Gd-III complexes. J. Am. Chem. Soc. 2001, 123, 10758-10759. [CrossRef]

27. Peters, J.A.; Huskens, J.; Raber, D.J. Lanthanide induced shifts and relaxation rate enhancements. Prog. Nucl. Mag. Res. Spec. 1996, 28, 283-350. [CrossRef]

28. Hunter, A.C. Molecular hurdles in polyfectin design and mechanistic background to polycation induced cytotoxicity. Adv. Drug Deliver. Rev. 2006, 58, 1523-1531. [CrossRef] 
29. Crich, S.G.; Alberti, D.; Szabo, I.; Aime, S.; Djanashvili, K. MRI Visualization of Melanoma Cells by Targeting Overexpressed Sialic Acid with a GdIII-dota-en-pba Imaging Reporter. Angew. Chem. Int. Edit. 2013, 52, 1161-1164. [CrossRef]

30. Shoichi, N.; Yuki, M.; Toshiya, S. Understanding the molecular structure of the sialic acid-phenylboronic acid complex by using a combined NMR spectroscopy and DFT study: Toward sialic acid detection at cell membranes. Chem. Open 2018, 7, 513-519.

31. Daly, W.; Poche, D. The preparation of N-Cardoxyanhydrides of Alpha-Amino-Acids using bis(trichloromethyl)carbonate. Tetrahedron Lett. 1988, 29, 5859-5862. [CrossRef]

Sample Availability: Samples of the compounds PLL-B-DTPA-Gd-Rodamine-DCA are available from the authors.

(C) 2019 by the authors. Licensee MDPI, Basel, Switzerland. This article is an open access article distributed under the terms and conditions of the Creative Commons Attribution (CC BY) license (http://creativecommons.org/licenses/by/4.0/). 